\title{
PX-12 inhibits the growth of A549 lung cancer cells via G2/M phase arrest and ROS-dependent apoptosis
}

\author{
BO RA YOU, HYE RIM SHIN and WOO HYUN PARK \\ Department of Physiology, Medical School, Research Institute for Endocrine Sciences, \\ Chonbuk National University, Jeonju 561-180, Republic of Korea \\ Received August 21, 2013; Accepted October 1, 2013
}

DOI: $10.3892 /$ ijo.2013.2152

\begin{abstract}
PX-12 (1-methylpropyl 2-imidazolyl disulfide) is an inhibitor of thioredoxin (Trx-1), which has antitumor effects. However, little is known about the toxicological effect of PX-12 on cancer cells. We investigated the anti-growth effects of PX-12 on A549 lung cancer cells in relation to reactive oxygen species (ROS) and glutathione (GSH) levels. Based on MTT assays, PX-12 inhibited the growth of A549 cells with an $\mathrm{IC}_{50}$ of approximately $20 \mu \mathrm{M}$ at $72 \mathrm{~h}$. DNA flow cytometric analysis indicated that PX-12 significantly induced the G2/M phase arrest of the cell cycle in A549 cells. This agent also induced apoptotic cell death, as demonstrated by Annexin V-FITC staining cells and the loss of mitochondrial membrane potential MMP $\left(\Delta \Psi_{\mathrm{m}}\right)$. In addition, the administration of Bax siRNA attenuated PX-12-induced A549 cell death. All the tested caspase inhibitors, especially Z-VAD significantly prevented apoptosis induced by PX-12. With respect to ROS and GSH levels, PX-12 increased ROS levels including $\mathrm{O}_{2}^{--}$in A549 cells and induced GSH depletion. N-acetyl cysteine (NAC) markedly reduced ROS levels in PX-12-treated A549 cells. NAC also prevented apoptotic cell death and GSH depletion induced by PX-12. This is the first report to show that PX-12 inhibits the growth of A549 cells via G2/M phase arrest, and Bax-mediated and ROS-dependent apoptosis.
\end{abstract}

Correspondence to: Professor Woo Hyun Park, Department of Physiology, Medical School, Chonbuk National University, Jeonju 561-180, Republic of Korea

E-mail: parkwh71@chonbuk.ac.kr

Abbreviations: Trx, thioredoxin; ROS, reactive oxygen species; GSH, glutathione; Z-VAD-FMK, benzyloxycarbonyl-Val-Ala-Aspfluormethylketone; Z-DEVD-FMK, benzyloxycarbonyl-Asp-GluVal-Asp-fluoromethylketone; Z-IETD-FMK, benzyloxycarbonylIle-Glu-Thr-Asp-fluoromethylketone; Z-LEHD-FMK, benzyloxycarbonyl-Leu-Glu-His-Asp-fluoromethylketone; NAC, N-acetyl cysteine; MMP $\left(\Delta \Psi_{\mathrm{m}}\right)$, mitochondrial membrane potential; MTT, 3-(4,5dimethylthiazol-2-yl)-2,5-diphenyltetrazolium bromide; FITC, fluorescein isothiocyanate; $\mathrm{PI}$, propidium iodide; $\mathrm{H}_{2} \mathrm{DCFDA}, 2^{\prime}$, 7'-dichlorodihydrofluorescein diacetate; DHE, dihydroethidium; CMFDA, 5-chloromethylfluorescein diacetate

Key words: PX-12, reactive oxygen species, thioredoxin, apoptosis, lung cancer

\section{Introduction}

Thioredoxin (Trx) is a small redox protein $(12 \mathrm{kDa})$ with two redox-active cysteine residues (C32 and $\mathrm{C} 35)$ in the active site (1). There are two main isoforms of Trx in mammalian cells; the cytoplasmic form, Trx-1 and the mitochondrial form, Trx-2 (2). These Trxs are reduced by thioredoxin reductase and NADPH following the reduction of oxidative target proteins $(3,4)$. Trx affects cell growth and proliferation via regulating the redox status in cells (5). Trx-1 is also implicated in cell survival, tumor development and angiogenesis $(6,7)$. Numerous studies demonstrated that overexpression of Trx is observed in many cancers such as gastric and breast cancers $(5,8)$. Therefore, Trx-1 inhibitors have been considered as novel anticancer drugs. In particular, PX-12 (1-methylpropyl 2-imidazolyl disulfide) is an irreversible Trx-1 inhibitor, which has an anti-tumor effect (9). PX-12 decreased the activity of Trx-1 by thioalkylating the critical cysteine residue (Cys73) in this protein or by increasing the dimerization of its oxidative form. In addition, PX-12 downregulates the expression of vascular endothelial growth factor via decreasing hypoxia-inducible factor- $1 \alpha$, consequently inhibiting metastasis of cancer cells $(10,11)$. Recently, PX-12 has been clinically tested in colorectal and pancreatic cancers $(12,13)$.

Lung cancer is a major cause of cancer death in the developed countries. Various novel therapeutic strategies are still currently under consideration since the clinical use of cytotoxic drugs is limited due to intrinsic or acquired resistant and toxicity (14). An increase in Trx-1 level is detected in lung cancer patients compared to the control group (15). In addition, it is reported that the high level of Trx-1 contributes to chemoresistance in lung cancer cells (16). However, little is known about the cellular effect of PX-12 in lung cancer. Therefore, in the present study we investigated the effects of PX-12 on cell growth and death in human lung cancer A549 cells with respect to reactive oxygen species (ROS) and glutathione (GSH) levels.

\section{Materials and methods}

Cell culture. Human lung adenocarcinoma A549 cells from the American Type Culture Collection (ATCC, Manassas, VA, USA) were maintained in a humidified incubator containing $5 \% \mathrm{CO}_{2}$ at $37^{\circ} \mathrm{C}$. A549 cells were cultured in RPMI-1640 (Sigma-Aldrich, St. Louis, MO, USA) supplemented with $10 \%$ 
fetal bovine serum (FBS; Sigma-Aldrich) and 1\% penicillinstreptomycin (Gibco BRL, Grand Island, NY, USA). Cells were routinely grown in $100-\mathrm{mm}$ plastic tissue culture dishes (Nunc. Roskilde, Denmark) and harvested with a solution of trypsin-EDTA (Gibco BRL) while in a logarithmic phase of growth.

Reagents. PX-12 was purchased from Tocris Bioscience (Bristol, UK) and was dissolved in dimethyl sulfoxide (DMSO; Sigma-Aldrich) at $100 \mathrm{mM}$ as a stock solution. The pan-caspase inhibitor (Z-VAD-FMK; benzyloxycarbonyl-Val-Ala-Asp-fluoromethylketone), caspase-3 inhibitor (Z-DEVD-FMK; benzyloxycarbonyl-Asp-Glu-Val-Asp-fluoromethylketone), caspase-8 inhibitor (Z-IETD-FMK; benzyloxycarbonyl-Ile-Glu-ThrAsp-fluoromethylketone) and caspase-9 inhibitor (Z-LEHDFMK; benzyloxycarbonyl-Leu-Glu-His-Asp-fluoromethylketone) were obtained from R\&D Systems, Inc. (Minneapolis, MN, USA) and were dissolved in DMSO at $10 \mathrm{mM}$ to serve as stock solutions. NAC was dissolved in the buffer $[20 \mathrm{mM}$ HEPES (pH 7.0)]. Based on the previous studies $(17,18)$, cells were pretreated with $15 \mu \mathrm{M}$ caspase inhibitors or $2 \mathrm{mM}$ NAC for $1 \mathrm{~h}$ prior to treatment with PX-12. DMSO $(0.03 \%)$ was used as a control vehicle and it did not affect cell growth or death.

Growth inhibition assay. The effect of PX-12 on cell growth was determined by measuring 3-(4,5-dimethylthiazol-2-yl)2,5-diphenyltetrazolium bromide (MTT; Sigma-Aldrich) absorbance in living cells as described previously (19). In brief, $1 \times 10^{4}$ cells per well were seeded in 96-well microtiter plates (Nunc). Following exposure to the designated doses of PX-12 for the indicated times, MTT solution [20 $\mu \mathrm{l}: 2 \mathrm{mg} / \mathrm{ml}$ in phosphate-buffered saline (PBS)] was added to each well of the 96-well plates. The plates were additionally incubated for $3 \mathrm{~h}$ at $37^{\circ} \mathrm{C}$. Medium was withdrawn from the plates by pipetting and $200 \mu \mathrm{l}$ DMSO was added to each well to solubilize the formazan crystals. The optical density was measured at $570 \mathrm{~nm}$ using a microplate reader (Synergy ${ }^{\mathrm{TM}}$ 2, BioTek Instruments Inc., Winooski, VT, USA).

Western blot analysis. The expression of proteins was evaluated using western blot analysis, as previously described (20). In brief, $1 \times 10^{6}$ cells in a $60-\mathrm{mm}$ culture dish (Nunc) were incubated with the designated doses of PX-12 for $72 \mathrm{~h}$. The cells were then washed in PBS and suspended in $5 \mathrm{Vol}$ of lysis buffer (20 mM HEPES. pH 7.9, 20\% glycerol, $200 \mathrm{mM}$ $\mathrm{KCl}, 0.5 \mathrm{mM}$ EDTA, $0.5 \%$ NP40, $0.5 \mathrm{mM}$ DTT, $1 \%$ protease inhibitor cocktail). Supernatant protein concentrations were determined using the Bradford method. Supernatant samples containing $30 \mu \mathrm{g}$ total protein were resolved by $15 \%$ SDS-PAGE gels depending on the size of target proteins, transferred to Immobilon-P PVDF membranes (Millipore, Billerica, MA, USA) by electroblotting and then probed with anti-PARP, anti-c-PARP, anti-Bcl-2, anti-Bax (Cell Signaling Technology Inc., Danvers, MA, USA), anti-Trx-1 and anti$\beta$-actin antibodies (Santa Cruz Biotechnology, Santa Cruz, CA, USA). Membranes were incubated with horseradish peroxidase-conjugated secondary antibodies. Blots were developed using an ECL kit (Amersham, Arlington Heights, IL, USA).
Measurement of Trx-1 activity. The Trx-1 activity was assessed using the ProteoStat ${ }^{\mathrm{TM}}$ Thioredoxin-1 assay kit according to the manufacturer's instructions (EnZo Life Science, Plymouth Meeting, PA, USA). In brief, $1 \times 10^{6}$ cells in 60 -mm culture dish (Nunc) were incubated with the indicated doses of PX-12 for $72 \mathrm{~h}$. The cells were then washed in PBS and suspended in $5 \mathrm{Vol}$ of lysis buffer (R\&D Systems, Inc.). Protein concentrations were determined using the Bradford method. Supernatant samples containing $20 \mu \mathrm{g}$ of total protein were used for determination of Trx-1 activity, and added to each well in 96-well microtiter plates (Nunc) with the insulin and DTT at $25^{\circ} \mathrm{C}$ for $30 \mathrm{~min}$. The fluorescence intensity of each well was determined using a fluorescence reader (Synergy 2).

Cell cycle and sub-G1 cell analysis. Cell cycle and sub-G1 cell analysis were determined by propidium iodide (PI, Ex/ $\mathrm{Em}=488 / 617 \mathrm{~nm}$; Sigma-Aldrich) staining as described previously (20). In brief, $1 \times 10^{6}$ cells in $60-\mathrm{mm}$ culture dish (Nunc) were incubated with the designated doses of PX-12 for $72 \mathrm{~h}$. Total cells including floating cells were then washed with PBS and fixed in $70 \%(\mathrm{v} / \mathrm{v})$ ethanol. Cells were washed again with PBS, then incubated with PI $(10 \mu \mathrm{g} / \mathrm{ml})$ with simultaneous RNase treatment at $37^{\circ} \mathrm{C}$ for 30 min. Cellular DNA content was measured using a FACStar flow cytometer (Becton-Dickinson, Franklin Lakes, NJ, USA) and analyzed by using lysis II and cellfit software (Becton-Dickinson).

Annexin V-FITC/PI staining for cell death detection. Apoptotic cell death was determined by staining cells with Annexin V-fluorescein isothiocyanate (FITC, Invitrogen Life Technologies, Camarillo, CA, USA; Ex/Em=488/519 nm) as described previously (21). In brief, $1 \times 10^{6}$ cells in $60-\mathrm{mm}$ culture dish (Nunc) were incubated with the designated doses of PX-12 for $72 \mathrm{~h}$ with or without $15 \mu \mathrm{M}$ each caspase inhibitor or $2 \mathrm{mM}$ NAC. Cells were washed twice with cold PBS and then resuspended in $500 \mu \mathrm{l}$ binding buffer (10 mM HEPES/ $\mathrm{NaOH} \mathrm{pH} \mathrm{7.4,} 140 \mathrm{mM} \mathrm{NaCl}, 2.5 \mathrm{mM} \mathrm{CaCl}_{2}$ ) at a concentration of $1 \times 10^{6} \mathrm{cells} / \mathrm{ml}$. Annexin V-FITC $(5 \mu \mathrm{l})$ and PI $(1 \mu \mathrm{g} / \mathrm{ml})$ were then added and the cells were analyzed with a FACStar flow cytometer.

Measurement of the mitochondrial membrane potential $\left(M M P ; \Delta \Psi_{m}\right)$. The MMP $\left(\Delta \Psi_{\mathrm{m}}\right)$ levels were measured by a rhodamine 123 fluorescent dye (Sigma-Aldrich; Ex/ $\mathrm{Em}=485 / 535 \mathrm{~nm})$ as described previously $(21,22)$. In brief, $1 \times 10^{6}$ cells in $60-\mathrm{mm}$ culture dish (Nunc) were incubated with the designated doses of PX-12 for $72 \mathrm{~h}$ with or without $15 \mu \mathrm{M}$ each caspase inhibitor or $2 \mathrm{mM}$ NAC. Cells were washed twice with PBS and incubated with rhodamine 123 $(0.1 \mu \mathrm{g} / \mathrm{ml})$ at $37^{\circ} \mathrm{C}$ for $30 \mathrm{~min}$. Rhodamine 123 staining intensity was determined by a FACStar flow cytometer. The cells that were rhodamine 123-negative were indicated to have lost $\operatorname{MMP}\left(\Delta \Psi_{\mathrm{m}}\right)$.

Transfection of cells with Bcl-2 and Bax siRNAs. Gene silencing of Bax and Bcl-2 was performed using a siRNA knockdown system. A non-specific control siRNA duplex [5'-CCUACGCC ACCAAUUUCGU(dTdT)-3'], Bcl-2 siRNA duplex [5'-CAGA AGUCUGGGAAUCGAU(dTdT)-3'] and Bax siRNA duplex [5'-GCUGGACAUUGGACUUCCU(dTdT)-3'] were purchased 

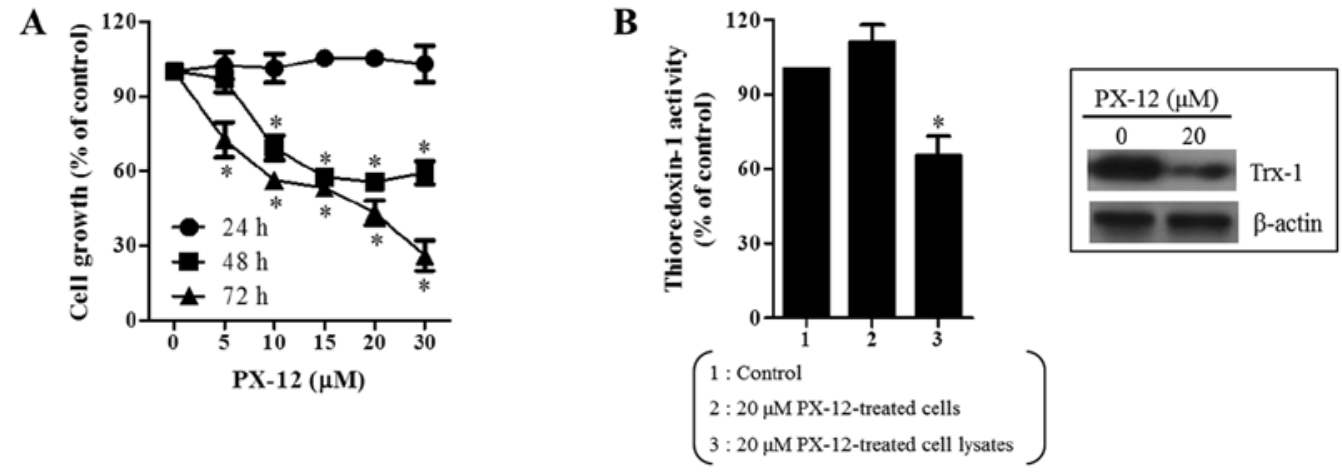

Figure 1. Effects of PX-12 on cell growth in A549 cells. Exponentially growing cells were treated with the indicated concentrations of PX-12 for $72 \mathrm{~h}$. (A) The graph shows cellular growth changes in A549 cells as assessed by MTT assays. (B) The graph shows Trx-1 activity in A549 cells. The inside figure indicates the level of Trx-1. " $\mathrm{p}<0.05$ compared with the control group.

from the Bioneer Corp. (Daejeon, Korea). In brief, $2.5 \times 10^{5}$ cells in 6-well plates (Nunc) were incubated in RPMI-1640 supplemented with $10 \%$ FBS. Following 12 h, cells $(\sim 30-40 \%$ confluence) in each well were transfected with the control, Bax or Bcl-2 siRNA [80 pmol in Opti-MEM (Gibco BRL)] using Lipofectamine 2000, according to the manufacturer's instructions (Invitrogen, Branford, CT, USA). One day later, cells were treated with or without $20 \mu \mathrm{M} \mathrm{PX}-12$ for additional $48 \mathrm{~h}$. The transfected cells were collected and used for western blot analysis, sub-G1 cells, Annexin V-FITC staining and MMP $\left(\Delta \Psi_{\mathrm{m}}\right)$ level measurements.

Detection of intracellular ROS levels. Intracellular ROS were detected by means of an oxidation-sensitive fluorescent probe dye, 2',7'-dichlorodihydrofluorescein diacetate (Ex/ Em=495/529 nm; Invitrogen Life Technologies) and dihydroethidium (DHE, Ex/Em=518/605 nm; Invitrogen Life Technologies) as previously described $(21,23)$. DHE is highly selective for $\mathrm{O}_{2}{ }^{-}$among ROS. In brief, $1 \times 10^{6}$ cells in $60-\mathrm{mm}$ culture dish (Nunc) were incubated with the designated doses of PX-12 for indicated times with or without $15 \mu \mathrm{M}$ each caspase inhibitor or $2 \mathrm{mM}$ NAC. Cells were then washed in PBS and incubated with $20 \mu \mathrm{M} \mathrm{H}_{2}$ DCFDA or DHE at $37^{\circ} \mathrm{C}$ for $30 \mathrm{~min} . \mathrm{H}_{2} \mathrm{DCFDA}$ or DHE fluorescence was assessed using a FACStar flow cytometer. ROS and $\mathrm{O}_{2}{ }^{--}$levels were expressed as mean fluorescence intensity, which was calculated by CellQuest software.

Detection of intracellular GSH. Cellular GSH levels were analyzed using a 5-chloromethylfluorescein diacetate dye (CMFDA, Ex/Em=522/595 nm; Invitrogen Life Technologies) as previously described $(23,24)$. In brief, $1 \times 10^{6}$ cells in $60-\mathrm{mm}$ culture dish (Nunc) were incubated with the designated doses of PX-12 for $72 \mathrm{~h}$ with or without $15 \mu \mathrm{M}$ each caspase inhibitor or $2 \mathrm{mM}$ NAC. Cells were then washed with PBS and incubated with $5 \mu \mathrm{M} \mathrm{CMFDA} \mathrm{at} 37^{\circ} \mathrm{C}$ for $30 \mathrm{~min}$. CMF fluorescence intensity was determined using a FACStar flow cytometer. Negative CMF staining (GSH-depletion) of cells is expressed as the percentage of (-) CMF cells.

Statistical analysis. Results represent the mean of at least three independent experiments (mean $\pm \mathrm{SD}$ ). Data were analyzed using Instat software (GraphPad Prism4, San Diego,
CA, USA). The Student's t-test or one-way analysis of variance with post hoc analysis using Tukey's multiple comparison test was used for parametric data. The statistical significance was defined as $\mathrm{p}<0.05$.

\section{Results}

Effects of PX-12 on the growth of A549 cells. We first examined the effect of PX-12 on the growth of A549 cells using MTT assays. After exposure to PX-12 for 24,48 and $72 \mathrm{~h}$, the growth of A549 cells dose-dependently decreased with an $\mathrm{IC}_{50}$ of $\sim 20 \mu \mathrm{M}$ at 48 and $72 \mathrm{~h}$ (Fig. 1A). In addition, it was observed that PX-12 as a Trx-1 inhibitor decreased the activity of Trx-1 in A549 cell lysate (Fig. 1B). Moreover, PX-12 decreased the level of Trx-1 expression in A549 cells at $72 \mathrm{~h}$ (Fig. 1B).

Effects of PX-12 on cell cycle distributions, cell death and MMP $\left(\Delta \Psi_{m}\right)$ in A549 cells. Because the growth inhibition of A549 cells caused by PX-12 can be explained by an arrest during the cell cycle progression, cell cycle distributions were examined at $72 \mathrm{~h}$. As shown in Fig. 2A, DNA flow cytometric analysis indicated that 5-20 $\mu \mathrm{M} \mathrm{PX}-12$ significantly induced a G2/M phase arrest of the cell cycle in A549 cells. In addition, PX-12 increased the percentages of sub-G1 cells in A549 cells in a dose-dependent manner at $72 \mathrm{~h}$ (Fig. 2B). This agent also increased the numbers of Annexin V-FITC-positive cells in A549 cells (Fig. 2C). The intact of poly(ADP-ribose) polymerase (PARP) and Bcl-2 levels were decreased by PX-12 (Fig. 2C). However, PX-12 increased Bax level in A549 cells at $72 \mathrm{~h}$ (Fig. 2C). Cell death is closely related to the collapse of the MMP $\left(\Delta \Psi_{\mathrm{m}}\right)(25)$. As expected, the loss of MMP $\left(\Delta \Psi_{\mathrm{m}}\right)$ was detected in PX-12 treated A549 cells (Fig. 2D).

Effect of Bcl-2 and Bax siRNAs on cell death and $M M P\left(\Delta \Psi_{m}\right)$ in PX-12-treated A549 cells. To investigate the effects of Bcl-2 and Bax on A549 cell death, A549 cells were transfected with either non-target control siRNA, Bcl-2 or Bax siRNA. As shown in Fig. 3A, the expression of Bcl-2 and Bax was clearly downregulated by the administration with each siRNA as compared with cells transfected with control siRNA. While Bax siRNA significantly prevented A549 cell death induced by PX-12, Bcl-2 siRNA slightly increased cell death in PX-12treated A549 cells (Fig. 3B and C). In addition, Bax siRNA 

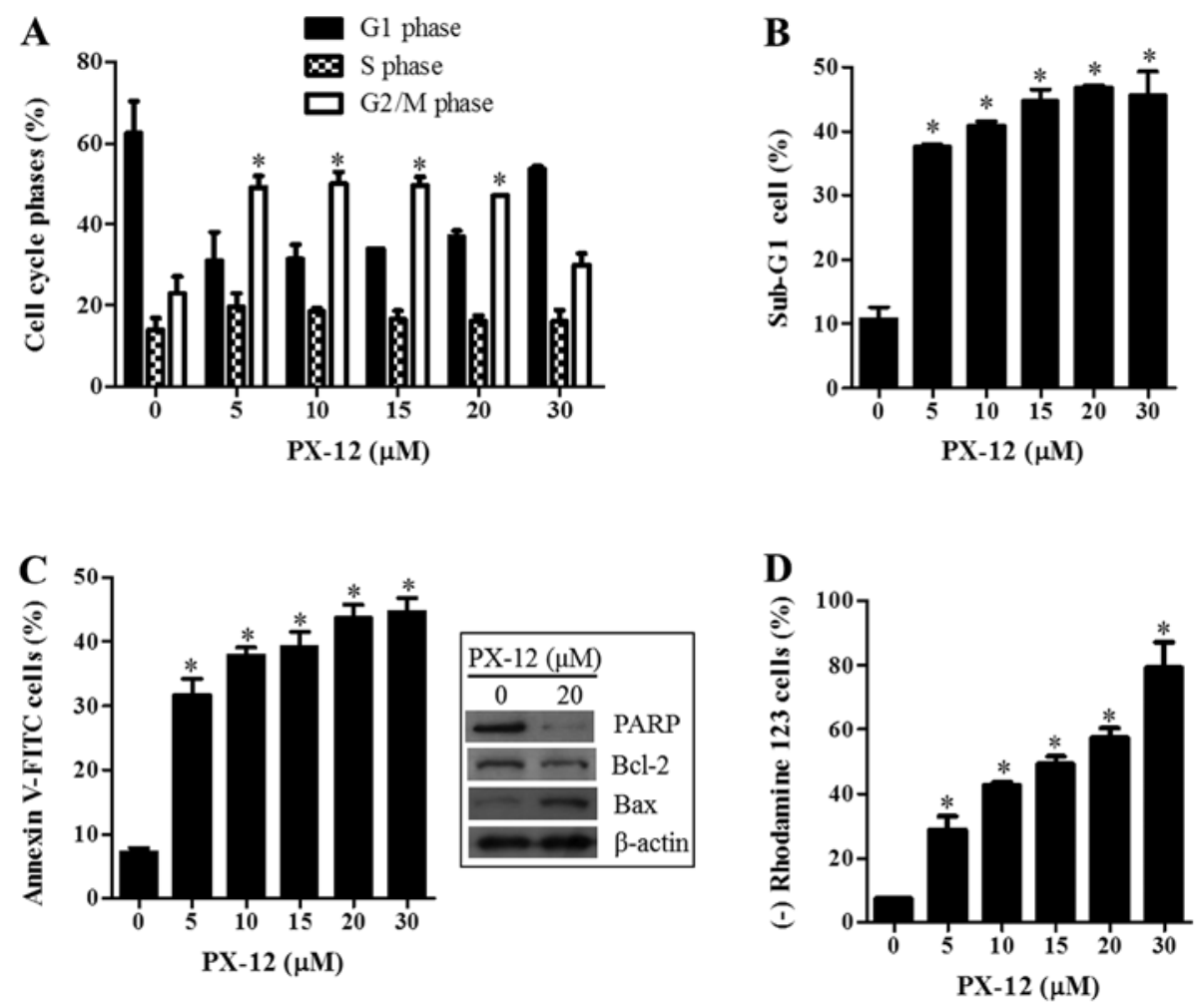

Figure 2. Effects of PX-12 on cell cycle distributions, cell death and MMP $\left(\Delta \Psi_{\mathrm{m}}\right)$ in A549 cells. Exponentially growing cells were treated with the indicated concentration of PX-12 for $72 \mathrm{~h}$. (A) The graph indicates changes in the cell cycle distribution as assessed by DNA flow cytometric analysis. (B and C) The graphs show the percentages of sub-G1 cells (B) and Annexin V-positive cells (C) as measured by FACStar flow cytometer. The inside figures show the levels of PARP, Bcl-2, Bax and $\beta$-actin proteins. (D) The graph shows the percentages of a rhodamine 123 negative [MMP $\left(\Delta \Psi_{\mathrm{m}}\right)$ loss] cells as measured by FACStar flow cytometer. " $\mathrm{p}<0.05$ compared with the control group.

A

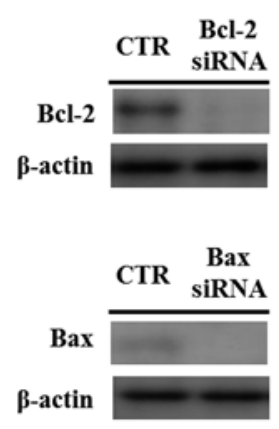

C

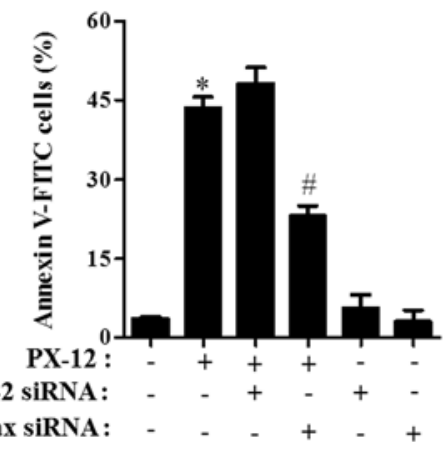

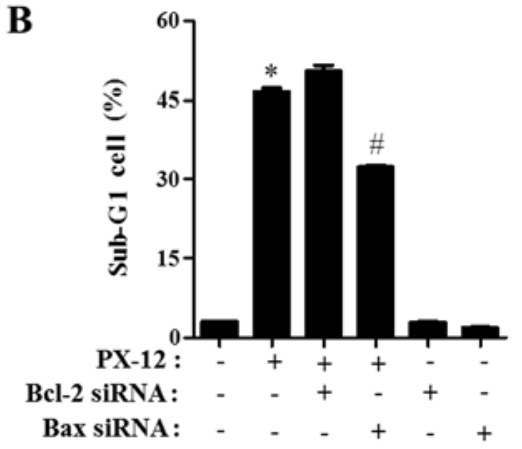

D

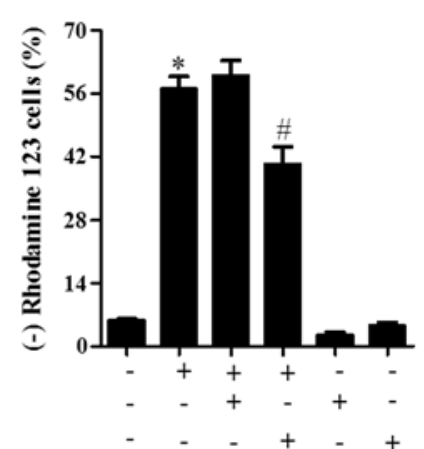

Figure 3. Effect of Bcl-2 and Bax siRNAs on cell death and MMP $\left(\Delta \Psi_{\mathrm{m}}\right)$ in PX-12-treated A549 cells. A549 cells ( $\sim 30-40 \%$ confluence) were transfected with non-target control (CTR), Bcl-2 or Bax siRNA. Twelve hours later, cells were treated with $20 \mu \mathrm{M} \mathrm{PX}-12$ for an additional incubation of $48 \mathrm{~h}$. (A) The expression of Bcl-2 and Bax was examined by western blot analysis. (B and C) The graphs show the percentages of sub-G1 (B) and Annexin V-positive cells (C). (D) The graph shows the percentages of a rhodamine 123-negative [MMP $\left(\Delta \Psi_{\mathrm{m}}\right)$ loss] cells. ${ }^{*} \mathrm{p}<0.05$ compared with the control group. ${ }^{*} \mathrm{p}<0.05$ compared with cells treated with PX-12 only. 

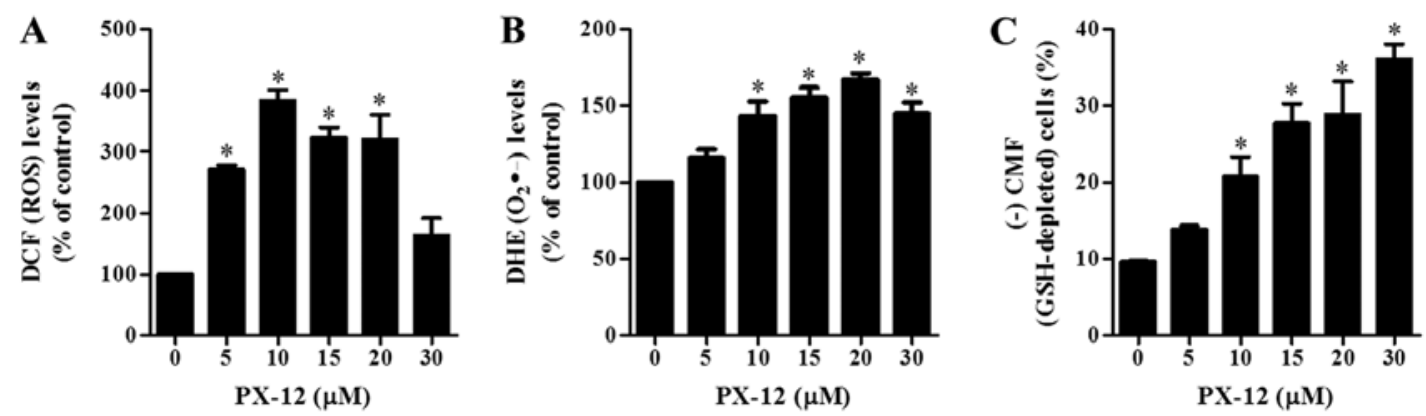

Figure 4. Effects of PX-12 on the intracellular ROS and GSH levels in A549 cells. Exponentially growing cells were treated with the indicated concentrations of PX-12 for $72 \mathrm{~h}$. ROS and GSH levels in A549 cells were measured using a FACStar flow cytometer. (A and B) The graphs indicate DCF (ROS) levels (\%) (A) and DHE $\left(\mathrm{O}_{2}^{*}\right)$ levels (\%) (B), compared with control cells. (C) The graph shows the percentages of (-) CMF (GSH-depleted) cells. "p<0.05 compared with the control group.
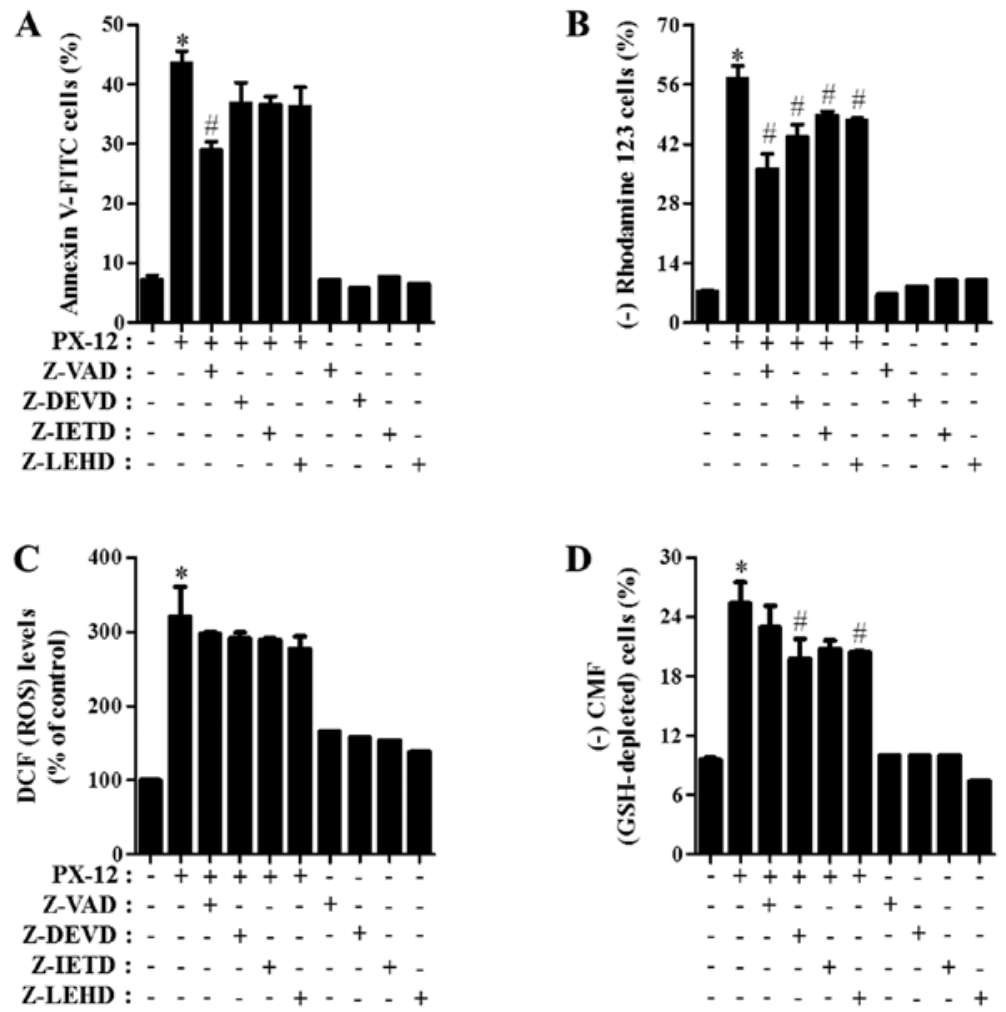

Figure 5. Effects of caspase inhibitors on cell death, MMP $\left(\Delta \Psi_{\mathrm{m}}\right)$, ROS and GSH levels in PX-12-treated A549 cells. Exponentially growing cells were treated with $20 \mu \mathrm{M}$ PX-12 for $72 \mathrm{~h}$ following 1-h pre-incubation of $15 \mu \mathrm{M}$ each caspase inhibitor. (A) The graph shows the percentages of Annexin V-positive cells in A549 cells. (B) The graph shows the percentages of a rhodamine 123 negative [MMP $\left(\Delta \Psi_{\mathrm{m}}\right)$ loss] cells. (C and D) The graphs indicate the percentages of ROS (DCF) levels (C) and (-) CMF (GSH-depleted) cells (D). " $\mathrm{p}<0.05$ compared with the control group. ${ }^{*} \mathrm{p}<0.05$ compared with cells treated with PX-12 only.

significantly attenuated the loss of MMP $\left(\Delta \Psi_{\mathrm{m}}\right)$ in PX-12treated A549 cells (Fig. 3D). However, Bcl-2 siRNA did not significantly affect the loss of MMP $\left(\Delta \Psi_{\mathrm{m}}\right)$ caused by PX-12 (Fig. 3D).

Effects of PX-12 on the intracellular ROS and GSH levels in A549 cells. The changes in intracellular ROS and GSH levels were investigated in A549 cells treated with PX-12 at $72 \mathrm{~h}$. As shown in Fig. 4A, PX-12 increased the intracellular ROS (DCF) levels in A549 cells at $72 \mathrm{~h}$. Moreover, red fluorescence derived from DHE reflecting the intracellular $\mathrm{O}_{2}{ }^{-}$levels significantly increased in PX-12-treated A549 cells at $72 \mathrm{~h}$ (Fig. 4B). When intracellular GSH levels were measured in PX-12-treated
A549 cells using a CMFDA dye, PX-12 significantly increased GSH-depleted cell number in A549 cells (Fig. 4C).

Effects of caspase inhibitors on cell death, MMP $\left(\Delta \Psi_{m}\right)$, ROS and GSH levels in PX-12-treated A549 cells. Which caspase was involved in A549 cell death induced by PX-12, was determined. For this experiment, we chose $20 \mu \mathrm{M}$ PX-12 as a suitable dose to differentiate the levels of cell death in the presence or absence of each caspase inhibitor. Based on a previous study (17), A549 cells were pretreated with $15 \mu \mathrm{M}$ of each caspase inhibitor for $1 \mathrm{~h}$ prior to treatment with PX-12. This dose did not significantly affect cell death in the control A549 cells (Fig. 5A). Treatment with all the tested caspase 
A

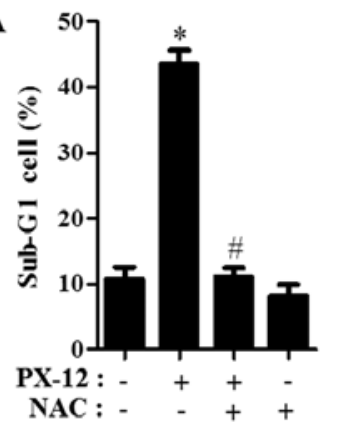

D

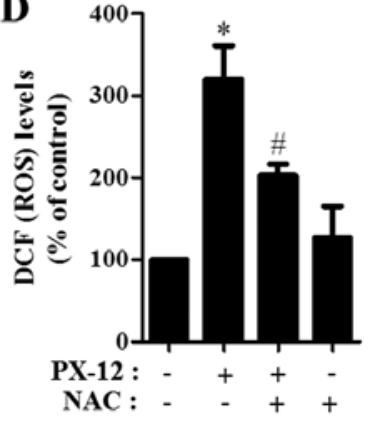

B
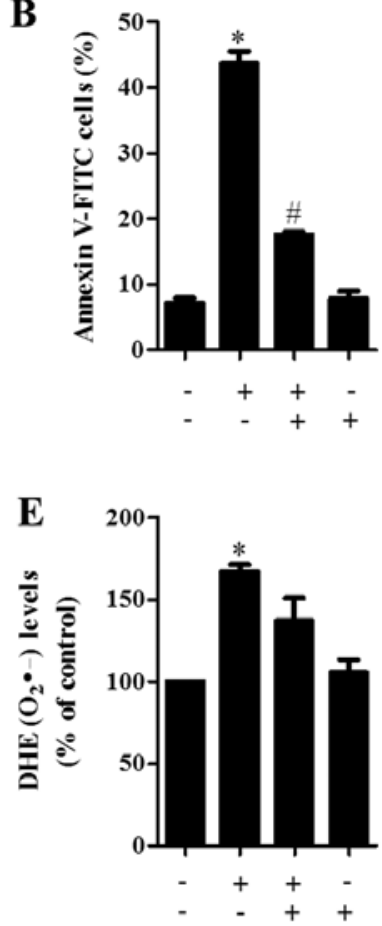

C
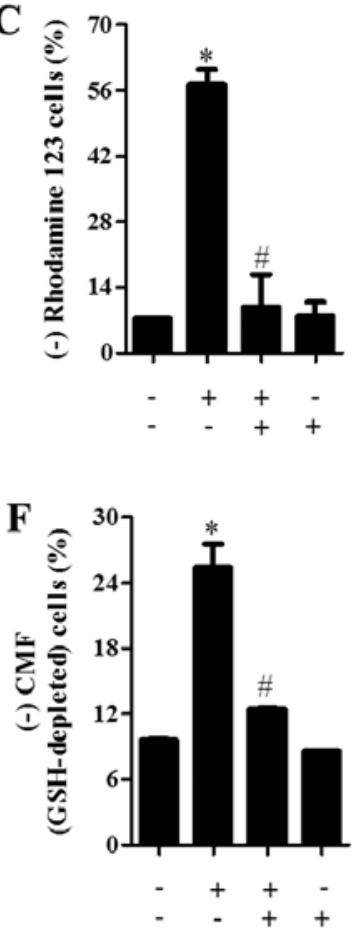

Figure 6. Effects of NAC on cell death, MMP $\left(\Delta \Psi_{\mathrm{m}}\right)$, ROS and GSH levels in PX-12-treated A549 cells. Exponentially growing cells were treated with $20 \mu \mathrm{M}$ PX-12 for $72 \mathrm{~h}$ following 1-h pre-incubation of $2 \mathrm{mM}$ NAC. (A and B) The graphs show the percentages of sub-G1 cells (A) and Annexin V-positive staining cells (B). (C) The graph shows the percentages of a rhodamine 123 negative [MMP $\left(\Delta \Psi_{\mathrm{m}}\right)$ loss] cells. (D and E) The graphs indicate DCF (ROS) levels (\%) (D) and DHE $\left(\mathrm{O}_{2}^{*}\right)$ levels $(\%)(\mathrm{E})$, compared with control cells. (F) The graph shows the percentages of (-) CMF (GSH-depleted) cells. "p $<0.05$ compared with the control group. $" \mathrm{p}<0.05$ compared with cells treated with PX-12 only.

inhibitors (Z-VAD for pan-caspases, Z-DEVD for caspase-3, Z-IETD for caspase-8 and Z-LEHD for caspase-9), especially Z-VAD showed significant rescue of A549 cells from PX-12induced apoptosis at $72 \mathrm{~h}$, as measured by the population of Annexin V-FITC-positive cells (Fig. 5A). Furthermore, all the caspase inhibitors significantly prevented the loss of MMP $\left(\Delta \Psi_{\mathrm{m}}\right)$ caused by PX-12 (Fig. $\left.5 \mathrm{~B}\right)$.

Whether the intracellular ROS and GSH levels in PX-12treated A549 cells were changed by treatment with each caspase inhibitor was investigated. As shown in Fig. 5C, all the caspase inhibitors marginally reduced ROS levels in PX-12-treated A549 cells. Moreover, these caspase inhibitors, especially Z-DEVD and Z-LEHD prevented GSH depletion in these cells (Fig. 5D).

Effects of NAC on cell death and MMP $\left(\Delta \Psi_{m}\right), R O S$ and $G S H$ levels in PX-12-treated A549 cells. Next, the effects of NAC on cell death and MMP $\left(\Delta \Psi_{\mathrm{m}}\right)$ in $20 \mu \mathrm{M}$ PX-12-treated A549 cells were assessed at $72 \mathrm{~h}$. As shown in Fig. 6A and B, NAC significantly decreased the percentages of sub-G1 cells and Annexin V-FITC-positive cells in PX-12-treated A549 cells. With respect to MMP $\left(\Delta \Psi_{\mathrm{m}}\right)$, NAC significantly attenuated the loss of MMP $\left(\Delta \Psi_{\mathrm{m}}\right)$ caused by PX-12 (Fig. 6C).

Furthermore, it was determined whether the intracellular ROS and GSH levels in PX-12-treated A549 cells were changed by treatment with NAC. NAC markedly decreased ROS levels including $\mathrm{O}_{2}{ }^{-}$in PX-12-treated A549 cells at $72 \mathrm{~h}$ (Fig. 6D and E). In relation to GSH levels, NAC markedly prevented GSH depletion caused by PX-12 in A549 cells (Fig. 6F).

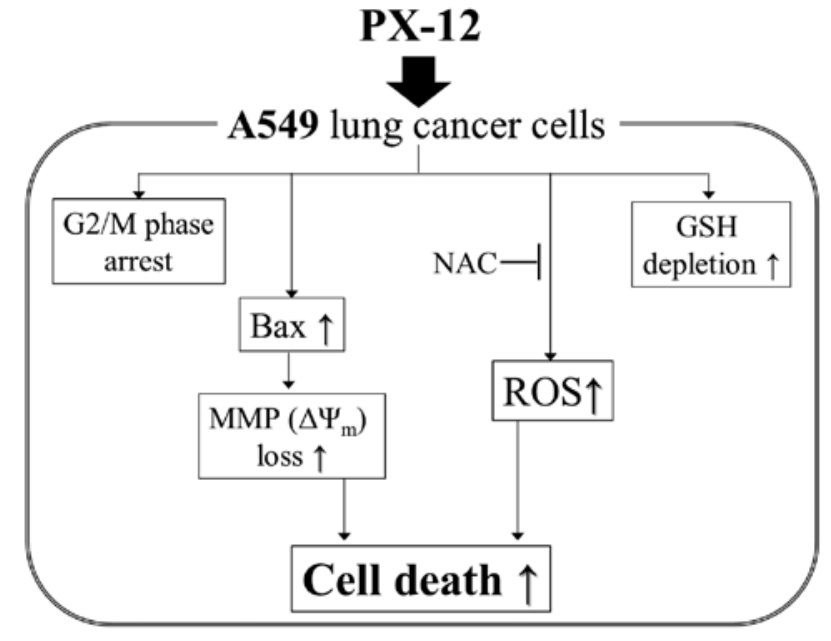

Figure 7. Schematic diagram of PX-12-induced cell growth inhibition in A549 cells.

\section{Discussion}

We investigated the effects of PX-12 in A549 lung cancer cells on cell growth and death in relation to ROS and GSH level. It was observed that PX-12 decreased the activity of Trx-1 in A549 cell lysate, indicating that PX-12 directly inhibited the activity of Trx-1 in this lysate. In addition, the level of Trx-1 expression was downregulated in PX12-treated A549 cells. Since the tight binding of PX-12 to Trx-1 leads to compositional changes in Trx-1 protein, it is possible that Trx-1 can be degraded via a ubiquitination system. However, the activity 
of Trx-1 was not reduced in PX-12-treated A549 cells at $72 \mathrm{~h}$. These results suggest that the activity of Trx-1 does not closely correspond with its level and the different effects of PX-12 on the activity of Trx-1 in cell lysate and cells are probably derived from the different functional bioavailability of this drug.

PX-12 inhibited the growth of A549 cells time- and dosedependently. PX-12 significantly induced a G2/M phase arrest of the cell cycle in A549 cells. Similarly, it has been found that PX-12 induces a G2/M phase arrest in cancer cells such as breast cancer, B-cell lymphoma $(1,26)$ and Calu-6 lung cancer cells (unpublished data). Therefore, the G2/M phase arrest in PX-12-treated cancer cells was an underlying mechanism to suppress cell growth and prolifeation. PX-12 also induced apoptosis in A549 cells and this drug strongly triggered the loss of MMP $\left(\Delta \Psi_{\mathrm{m}}\right)$. These results supported that apoptosis is closely related to the collapse of $\operatorname{MMP}\left(\Delta \Psi_{\mathrm{m}}\right)(27)$.

A high ratio of Bax to Bcl-2 has been known to be a main trigger in the collapse of MMP $\left(\Delta \Psi_{\mathrm{m}}\right)$ and apoptosis in cells (28). Likewise, the levels of Bcl-2 and Bax were downregulated and upregulated in PX-12-treated A549 cells, respectively. Moreover, the administration of Bax siRNA prevented A549 cell death caused by PX-12 whereas that of Bcl-2 siRNA did not strongly affect apoptosis and $\operatorname{MMP}\left(\Delta \Psi_{\mathrm{m}}\right)$ in PX-12 treated A549 cells. Therefore, PX-12 seemed to induce apoptosis in A549 cells depending on the upregulation of Bax protein. When determined which caspases were involved in apoptosis in PX-12-treated A549 cells, all the tested caspase inhibitors, especially Z-VAD prevented PX-12-induced A549 cell death. These data demonstrated that mitochondrial intrinsic pathway as well as death receptor extrinsic pathway together are necessary for the complete induction of apoptosis in PX-12-treated A549 cells. In addition, all the caspase inhibitors markedly attenuated the loss of MMP $\left(\Delta \Psi_{\mathrm{m}}\right)$ caused by PX-12. These results suggest that the loss of $\mathrm{MMP}\left(\Delta \Psi_{\mathrm{m}}\right)$ induced by PX-12 is a crucial step to fully induce apoptosis in A549 cells.

PX-12 as an inhibitor of TrX-1 can affect the status of redox in cells. It is reported that PX-12 induces oxidative stress (29). Likewise, the intracellular ROS levels including $\mathrm{O}_{2}{ }^{-}$ significantly increased in PX-12-treated A549 cells at $72 \mathrm{~h}$. All caspase inhibitors showing anti-apoptotic effects attenuated ROS levels in PX-12-treated A549 cells. Furthermore, NAC markedly prevented apoptotic cell death and the loss of MMP $\left(\Delta \Psi_{\mathrm{m}}\right)$ in PX-12-treated A549 cells, accompanied by decreasing ROS levels including $\mathrm{O}_{2}^{-{ }^{-}}$in these cells. Taken together, these results suggest that PX-12-induced cell death is mediated by oxidative stress. GSH is an important intracellular antioxidant that protects cells from damage caused by free radicals, peroxides and toxins. It is able to clear away $\mathrm{O}_{2}{ }^{-}$and provide electrons for glutathione peroxidase to reduce $\mathrm{H}_{2} \mathrm{O}_{2}$ to $\mathrm{H}_{2} \mathrm{O}$. Apoptotic effects are inversely comparative to GSH content (30,31). Similarly, PX-12 increased the percentages of GSH-depleted cells in A549 cells at $72 \mathrm{~h}$. NAC and caspase inhibitors markedly prevented the depletion of GSH in PX-12-treated A549 cells. However, BSO, which is an inhibitor of GSH synthesis, did not affect apoptotic cell death in A549 cells (data not shown). Therefore, the loss of GSH content seemed to be necessary but not sufficient to induce apoptosis in PX-12-treated A549 cells.

In conclusion, depicted in Fig. 7, it is the first report that PX-12 inhibited the growth of A549 lung cancer cells via
G2/M phase arrest, and Bax-mediated and ROS-dependent apoptosis.

\section{Acknowledgements}

This study was supported by the National Research Foundation of Korea (NRF) grant funded by the Korea government (MSIP) (No. 2008-0062279) and supported by the Basic Science Research Program through the National Research Foundation of Korea (NRF) funded by the Ministry of Education (2013006279).

\section{References}

1. Li C, Thompson MA, Tamayo AT, et al: Over-expression of Thioredoxin-1 mediates growth, survival, and chemoresistance and is a druggable target in diffuse large B-cell lymphoma. Oncotarget 3: 314-326, 2012.

2. Yang J, Li C, Ding L, Guo Q, You Q and Jin S: Gambogic acid deactivates cytosolic and mitochondrial thioredoxins by covalent binding to the functional domain. J Nat Prod 75: 1108-1116, 2012.

3. Chae JS, Gil Hwang S, Lim DS and Choi EJ: Thioredoxin-1 functions as a molecular switch regulating the oxidative stressinduced activation of MST1. Free Radic Biol Med 53: 2335-2343, 2012.

4. Ungerstedt J, Du Y, Zhang H, Nair D and Holmgren A: In vivo redox state of human thioredoxin and redox shift by the histone deacetylase inhibitor suberoylanilide hydroxamic acid (SAHA). Free Radic Biol Med 53: 2002-2007, 2012.

5. Lim JY, Yoon SO, Hong SW, Kim JW, Choi SH and Cho JY: Thioredoxin and thioredoxin-interacting protein as prognostic markers for gastric cancer recurrence. World J Gastroenterol 18: 5581-5588, 2012.

6. Pramanik KC and Srivastava SK: Apoptosis signal-regulating kinase 1-thioredoxin complex dissociation by capsaicin causes pancreatic tumor growth suppression by inducing apoptosis. Antioxid Redox Signal 17: 1417-1432, 2012.

7. Dunn LL, Buckle AM, Cooke JP and Ng MK: The emerging role of the thioredoxin system in angiogenesis. Arterioscler Thromb Vasc Biol 30: 2089-2098, 2010.

8. Cha MK, Suh KH and Kim IH: Overexpression of peroxiredoxin I and thioredoxin 1 in human breast carcinoma. J Exp Clin Cancer Res 28: 93, 2009.

9. Wondrak GT: Redox-directed cancer therapeutics: molecular mechanisms and opportunities. Antioxid Redox Signal 11: 3013-3069, 2009

10. Welsh SJ, Williams RR, Birmingham A, Newman DJ, Kirkpatrick DL and Powis G: The thioredoxin redox inhibitors 1-methylpropyl 2-imidazolyl disulfide and pleurotin inhibit hypoxia-induced factor lalpha and vascular endothelial growth factor formation. Mol Cancer Ther 2: 235-243, 2003.

11. Mukherjee A and Martin SG: The thioredoxin system: a key target in tumour and endothelial cells. Br J Radiol 81 (Spec No. 1): S57-S68, 2008

12. Baker AF, Adab KN, Raghunand N, et al: A phase IB trial of 24-hour intravenous PX-12, a thioredoxin-1 inhibitor, in patients with advanced gastrointestinal cancers. Invest New Drugs 31: 631-641 2013.

13. Ramanathan RK, Kirkpatrick DL, Belani CP, et al: A Phase I pharmacokinetic and pharmacodynamic study of PX-12, a novel inhibitor of thioredoxin-1, in patients with advanced solid tumors. Clin Cancer Res 13: 2109-2114, 2007.

14. Petty RD, Nicolson MC, Kerr KM, Collie-Duguid E and Murray GI: Gene expression profiling in non-small cell lung cancer: from molecular mechanisms to clinical application. Clin Cancer Res 10: 3237-3248, 2004.

15. Fernandes AP, Capitanio A, Selenius M, Brodin O, Rundlof AK and Bjornstedt M: Expression profiles of thioredoxin family proteins in human lung cancer tissue: correlation with proliferation and differentiation. Histopathology 55: 313-320, 2009.

16. Wangpaichitr M, Sullivan EJ, Theodoropoulos G, et al: The relationship of thioredoxin-1 and cisplatin resistance: its impact on ROS and oxidative metabolism in lung cancer cells. Mol Cancer Ther 11: 604-615, 2012.

17. Han YH, Kim SZ, Kim SH and Park WH: Pyrogallol inhibits the growth of lung cancer Calu- 6 cells via caspase-dependent apoptosis. Chem Biol Interact 177: 107-114, 2009. 
18. Han $\mathrm{YH}$ and Park WH: The effects of $\mathrm{N}$-acetyl cysteine, buthionine sulfoximine, diethyldithiocarbamate or 3-amino1,2,4-triazole on antimycin A-treated Calu-6 lung cells in relation to cell growth, reactive oxygen species and glutathione. Oncol Rep 22: 385-391, 2009.

19. Han YH, Moon HJ, You BR, Kim SZ, Kim SH and Park WH: Effects of carbonyl cyanide p-(trifluoromethoxy) phenylhydrazone on the growth inhibition in human pulmonary adenocarcinoma Calu-6 cells. Toxicology 265: 101-107, 2009.

20. You BR and Park WH: Zebularine inhibits the growth of HeLa cervical cancer cells via cell cycle arrest and caspase-dependent apoptosis. Mol Biol Rep 39: 9723-9731, 2012.

21. Han YH, Moon HJ, You BR and Park WH: The effect of MG132, a proteasome inhibitor on HeLa cells in relation to cell growth, reactive oxygen species and GSH. Oncol Rep 22: 215-221, 2009.

22. Han YH, Kim SH, Kim SZ and Park WH: Carbonyl cyanide p-(trifluoromethoxy) phenylhydrazone (FCCP) as an $\mathrm{O}_{2}\left(*_{-}\right)$ generator induces apoptosis via the depletion of intracellular GSH contents in Calu-6 cells. Lung Cancer 63: 201-209, 2009.

23. Han YH and Park WH: Propyl gallate inhibits the growth of $\mathrm{HeLa}$ cells via regulating intracellular GSH level. Food Chem Toxicol 47: 2531-2538, 2009.

24. You BR and Park WH: Gallic acid-induced lung cancer cell death is related to glutathione depletion as well as reactive oxygen species increase. Toxicol In Vitro 24: 1356-1362, 2010.
25. Griffiths EJ: Mitochondria - potential role in cell life and death. Cardiovasc Res 46: 24-27, 2000.

26. Vogt A, Tamura K, Watson S and Lazo JS: Antitumor imidazolyl disulfide IV-2 causes irreversible G(2)/M cell cycle arrest without hyperphosphorylation of cyclin-dependent kinase Cdk1. J Pharmacol Exp Ther 294: 1070-1075, 2000.

27. Yang J, Liu X, Bhalla K, et al: Prevention of apoptosis by Bcl-2: release of cytochrome $\mathrm{c}$ from mitochondria blocked. Science 275: 1129-1132, 1997.

28. Martinou JC and Youle RJ: Mitochondria in apoptosis: Bcl-2 family members and mitochondrial dynamics. Dev Cell 21: 92-101, 2011.

29. Lee YJ, Kim JH, Chen J and Song JJ: Enhancement of metabolic oxidative stress-induced cytotoxicity by the thioredoxin inhibitor 1-methylpropyl 2-imidazolyl disulfide is mediated through the ASK1-SEK1-JNK1 pathway. Mol Pharmacol 62: 1409-1417, 2002.

30. Estrela JM, Ortega A and Obrador E: Glutathione in cancer biology and therapy. Crit Rev Clin Lab Sci 43: 143-181, 2006.

31. You BR and Park WH: Arsenic trioxide induces human pulmonary fibroblast cell death via increasing ROS levels and GSH depletion. Oncol Rep 28: 749-757, 2012. 